\title{
HETEROSIS IN F1 GENERATIONS OF TWO INDICA RICE CROSSES FOR GROWTH AND YIELD CHARACTERISTICS
}

\author{
U. I. P. Perera ${ }^{1}$, A. P. Bentota ${ }^{1}$, D. Ratnasekara ${ }^{2}$ and S. G. J. N. Senanayake ${ }^{2}$
}

\begin{abstract}
Rice (Oryza sativa L.) is the main food crop for more than half of the world population. Use of heterosis is one of the greatest practical achievements of plant breeding. Two single crosses, Bg 379-2 x Mu 8-7 (Cross 1) and Bg 379-2 x Bw 400 (Cross 2) were chosen to study the heterosis and genetic effects in yield related agronomic characters of rice. $F_{1}$ hybrids along with their parents were evaluated in a Randomized Complete Block Design with four replicates. Cross 1 showed significant heterobeltiosis for leaf width $(L W)$, panicle length $(P L)$ and plant height (PH) while Cross 2 showed significant heterobeltiosis for LW, culm length (CL), and PH. Additive genetic effect is higher than the dominance effect in days to $50 \%$ flowering $(D F), C L$ and panicles per plant (PP) in Cross 1, while dominance effect is higher than the additive genetic effect in seedling height, LW, CL and PH in Cross 2. Bg 379-2 x Mu 8-7 is a more potential cross that agreed with breeding objectives, especially to extract short age high yielding breeding lines.
\end{abstract}

Key words; Genetic effects, Heterobeltiosis, Heterosis, Hybrid.

\section{INTRODUCTION}

Rice (Oryza sativa L.) is the staple crop of nearly half of the world's population, and is particularly important in Asia, where approximately $90 \%$ of world's rice is produced and consumed (Zeigler and Barclay, 2008). The studies on the use of heterosis in rice crop improvement were limited as rice is a self pollinated crop. However, the heterosis has been a powerful tool in the evolution of plants and has been exploited extensively in crop production (Birchler et al., 2003). According to Alam et al., (2004) the exploitation of heterosis has been the greatest practical achievement of the science of genetics and plant breeding. In rice, heterosis was first reported by Jones (1926) who observed that some F1 hybrids had more culms and higher yields than their parents. However, heterosis in rice was first exploited and commercially utilized in China (Yuan et al., 1994). Although rice is a naturally self pollinated crop, strong heterosis is observed in their $\mathrm{F}_{1}$ hybrids (Parvez, 2006). Kim 1985 reported that heterosis in rice grain yield was mainly due to comparatively more spikelets per panicle, higher thousand grain weight, higher number of panicles per hill, higher number of filled grains etc. The presence of sufficient heterosis is an important prerequisite for successful production of hybrid varieties. Both positive and negative heterosis is useful in crop improvement, depending on the breeding objectives. In general, positive heteosis is desired for yield and negative heterosis for early maturity (Nuruzzaman et al., 2002).

Today the possibility of improving grain yield in rice through conventional breeding

\footnotetext{
1 Grain Legumes and Oil crops Research and Development Centre, Angunakolapelessa, Sri Lanka.

2 Department of Agricultural Biology, Faculty of Agriculture, University of Ruhuna, Mapalana,

Kamburupitiya, Sri Lanka.
} 
is limited. This effort in developing newly improved varieties can be expressed as exploitation of additive genetic variability in plant breeding (Abeysiriwardena, 2003). Thus, rice breeders have to look for alternative genetic mechanisms to improve the genetic potential of the rice with respect to grain yield. Therefore, studies on heterosis which is based on non-additive genetic variability of yield related characteristics are very much important for further improvement of rice varieties. Heterosis is expressed in three ways; depending on the criteria used to compare the performance of a hybrid (Gupta, 2000). These are mid parent heterosis (the performance of $F_{1}$ compared with the average performance of its parents), heterobeltiosis (the performance of $\mathrm{F}_{1}$ compared with that of the best parent in the cross) and standard heterosis (the performance of F1 compared with the best conventional variety in the region). The objective of this study was to study the heterosis and genetic effects of agronomic characteristics related to yield in four indica rice varieties in Sri Lanka. As the crosses were made to develop recombinant inbred lines that are superior to their better parents, heterobeltiosis was used in this study.

\section{MATERIALS AND METHOD}

Two single crosses, $\mathrm{Bg} 379-2 \times \mathrm{Mu} 8-7$ (Cross 1) and Bg 379-2 x Bw 400 (Cross 2) were randomly chosen from the crosses made to develop improved rice varieties at the Regional Rice Research and Development Centre, Bombuwala. Cross 1 and cross 2 have been made to obtain short and long aged plants, respectively. F1 seeds of $\mathrm{Bg} 379-2$ $\mathrm{x} \mathrm{Mu} \mathrm{8-7} \mathrm{and} \mathrm{Bg} \mathrm{379-2} \mathrm{x} \mathrm{Bw} 400$ and their parental varieties were sown in trays and after fourteen days they were transplanted in the field in rows at the spacing of $15 \times 40 \mathrm{~cm}$ in a Randomized Complete Block Design with four replicates. Nineteen seedlings of each parent variety and F1 hybrid were established with single seedling per hill in each row. Irrigation and manual weeding was done when necessary and fertilizer and pesticides were applied according to the recommendations of the Department of Agriculture, Sri Lanka. Data were recorded on ten plants selected at random from each row in each replicate on the following morphological traits. The values are means \pm SD of 40 measurements from four independent replicates.

Seedling vigor (SV) was measured as seedling height taken from randomly selected ten plants from each line after two and three weeks of transplanting. Leaf length (LL) was measured from the topmost leaf blade below the flag leaf while the leaf width (LW) was measured at the widest portion of the blade from the same leaf.

The height from ground level to the base of the panicle at maturity was taken as the culm length. Panicle length (PL) was measured from base to the tip of the panicle at maturity. Days to $50 \%$ flowering (DF) was taken as number of days from the date of sowing to the $50 \%$ flowering at the flowering stage. Number of tillers per plant (TN) was counted from randomly selected ten plants from each replicate at the late vegetative stage and number of panicles per plant (PN) was counted from the plants selected to get tiller count. Plant height $(\mathrm{PH})$ was taken from ground level to the tip of the leaf of the tallest tiller at maturity. Total yield of all the panicles in a plant was measured at $14 \%$ moisture level to get the panicle weight (PW) per plant.

\section{RESULTS AND DISCUSSION}

Means of yield related agronomic characteristics of parents $\left(\mathrm{P}_{1}\right.$ and $\left.\mathrm{P}_{2}\right)$ and $\mathrm{F}_{1} \mathrm{~S}$ along with estimated heterobeltiosis of each characteristic of the Cross 1 (Bg 379-2x Mu 8-7) and the Cross 2 (Bg 379-2x Bw 400) are given in Table 01 and Table 02 respectively. 
Table 01: Means of yield related agronomic characteristics of parents $\left(P_{1}\right.$ and $\left.P_{2}\right)$ and $F_{1}$ and estimated heterobeltiosis of each characteristic of the cross between $\mathrm{Bg}$ 379-2 and $\mathrm{Mu}$ 8-7

\begin{tabular}{|c|c|c|c|c|c|c|c|c|c|c|}
\hline \multirow{2}{*}{$\begin{array}{c}\text { Population/ } \\
\text { Heterosis }\end{array}$} & \multicolumn{10}{|c|}{ Characteristic } \\
\hline & $\mathrm{SH}+$ & $\mathrm{DF} \ddagger$ & LL & LW & CL + & PL & $\mathrm{PH}+$ & $\mathrm{TP} \dagger$ & $\mathrm{PP} \ddagger$ & PW \\
\hline \multirow{3}{*}{$\mathrm{P} 1$} & $(\mathrm{~cm})$ & (days) & $(\mathrm{cm})$ & $(\mathrm{cm})$ & $(\mathrm{cm})$ & $(\mathrm{cm})$ & $(\mathrm{cm})$ & (No.) & (No.) & (g) \\
\hline & 18.5 & 76.2 & 41.4 & 1.4 & 73.3 & 26.7 & 99.1 & 11.5 & 10.1 & 50.9 \\
\hline & \pm 6.0 & \pm 0.1 & \pm 1.66 & \pm 1.85 & \pm 2.62 & \pm 3.3 & \pm 6.41 & \pm 1.97 & \pm 2.01 & 17.22 \\
\hline \multirow[t]{2}{*}{$\mathrm{P} 2$} & 17.6 & 95.7 & 37.6 & 1.2 & 68.4 & 25.8 & 95.1 & 11.8 & 9.8 & 31.8 \\
\hline & \pm 3.55 & \pm 0.09 & \pm 7.54 & \pm 1.66 & \pm 2.6 & \pm 7.63 & \pm 0.23 & \pm 2.15 & \pm 0.96 & \pm 6.6 \\
\hline \multirow[t]{2}{*}{$\mathrm{F} 1$} & 24.9 & 77 & 42.3 & 1.7 & 70.9 & 31.0 & 102 & 11.8 & 9.8 & 46.7 \\
\hline & \pm 3.5 & \pm 0.14 & \pm 7.05 & \pm 7.57 & \pm 3.46 & \pm 4.71 & \pm 14.3 & \pm 2.26 & \pm 0.82 & \pm 11.2 \\
\hline P1 vs. P2 & NS & * & * & $*$ & * & NS & $*$ & NS & NS & $*$ \\
\hline P1 vs. F1 & $*$ & - & NS & $*$ & - & $*$ & $*$ & - & - & - \\
\hline HET & 0.15 & 0.01 & 0.02 & 0.2 & -0.03 & 0.16 & 0.03 & 0.02 & -0.02 & -0.08 \\
\hline
\end{tabular}

$\mathrm{SH}=$ Seedling height, $\mathrm{DF}=$ Days to $50 \%$ flowering, $\mathrm{LL}=$ Leaf length, $\mathrm{LW}=$ Leaf width, $\mathrm{CL}=\mathrm{Culm}$ length, $\mathrm{PL}=\mathrm{Panicle}$ length, $\mathrm{PH}=\mathrm{Plant}$ height, $\mathrm{TP}=\mathrm{No}$. of tillers per plant, $\mathrm{PP}=$ No. of panicles per plant, $\mathrm{PW}=\mathrm{Panicle}$ weight

NS $=$ Not Significant $\quad \pm=$ Values are standard errors $\quad *=$ Significance at $5 \%$ level $\quad-=$ Absence of heterosis $\$=$ Higher scoring parent was Mu 8-7 and for the other characters the higher scoring parent was Bg 379-2 HET $=$ Heterobeltiosis

Table 02: Means of yield related agronomic characteristics of parents $\left(P_{1}\right.$ and $\left.P_{2}\right)$ and $F_{1}$ and estimated heterobeltiosis of each characteristic of the cross between Bg 379-2 and Bw 400

\begin{tabular}{|c|c|c|c|c|c|c|c|c|c|c|}
\hline \multirow{2}{*}{$\begin{array}{l}\text { Population/ } \\
\text { Heterosis }\end{array}$} & \multicolumn{10}{|c|}{ Characteristic } \\
\hline & $\mathrm{SH}$ & $\mathrm{DF}$ & LL & LW & $\mathrm{CL}+$ & PL & $\mathrm{PH} \$$ & $\mathrm{TP} \ddagger$ & $\mathrm{PP} \ddagger$ & PW \\
\hline \multirow{3}{*}{ P1 } & $(\mathrm{cm})$ & (days) & $(\mathrm{cm})$ & $(\mathrm{cm})$ & $(\mathrm{cm})$ & $(\mathrm{cm})$ & $(\mathrm{cm})$ & (No.) & (No.) & (g) \\
\hline & 20.2 & 95.5 & 41.4 & 1.4 & 86.7 & 26.7 & 116.1 & 11.3 & 9.8 & 50.9 \\
\hline & \pm 4.26 & \pm 0.14 & \pm 1.66 & \pm 1.85 & \pm 3.75 & \pm 3.3 & \pm 3.36 & \pm 2.57 & \pm 2.15 & 17.22 \\
\hline \multirow[t]{2}{*}{$\mathrm{P} 2$} & 17.6 & 95.7 & 58.3 & 1.4 & 68.4 & 26.4 & 95.1 & 11.8 & 9.8 & 40.5 \\
\hline & \pm 3.55 & \pm 0.09 & \pm 1.66 & \pm 1.53 & \pm 2.6 & \pm 3.3 & \pm 0.23 & \pm 2.15 & \pm 0.96 & \pm 14.53 \\
\hline \multirow[t]{2}{*}{ F1 } & 24.2 & 88.7 & 53.2 & 2.1 & 96.1 & 28.3 & 124.3 & 11.2 & 9.3 & 25.6 \\
\hline & \pm 9.05 & \pm 0.12 & \pm 3.28 & \pm 1.36 & \pm 3.82 & \pm 4.45 & \pm 20.5 & \pm 2.07 & \pm 2.12 & \pm 5.95 \\
\hline P1 vs. P2 & * & NS & * & NS & $*$ & * & $*$ & NS & NS & * \\
\hline P1 vs. F1 & $*$ & - & - & $*$ & * & - & $*$ & NS & - & - \\
\hline HET & 0.03 & -0.07 & -0.09 & 0.45 & 0.11 & -0.04 & 0.07 & -0.01 & -0.05 & -0.49 \\
\hline
\end{tabular}

$\mathrm{SH}=$ Seedling height, $\mathrm{DF}=$ Days to $50 \%$ flowering, $\mathrm{LL}=$ Leaf length, $\mathrm{LW}=$ Leaf width, $\mathrm{CL}=$ Culm length, $\mathrm{PL}=$ Panicle length, $\mathrm{PH}=\mathrm{Plant}$ height, $\mathrm{TP}=$ Number of tillers per plant, $\mathrm{PP}=$ Number of panicles per plant, $\mathrm{PW}=\mathrm{Panicle}$ weight NS $=$ Not Significant $\quad \pm=$ Values are standard errors $\quad *=$ Significance at $5 \%$ level $\quad-=$ Absence of heterosis $\$=$ Higher scoring parent was $\mathrm{Bw} 400$ and for the other characters the higher scoring parent was $\mathrm{Bg} 379-2$ HET $=$ Heterobeltiosis 


\section{Comparison between parents and their $F_{1}$}

Two parents (Bg 379-2 and $\mathrm{Mu} 8-7)$ were not significantly different for seedling vigor and $\mathrm{F}_{1}$ seedlings were more vigorous than the parents in cross 1 . With respect to leaf length, $\mathrm{Bg} 379-2$ and $\mathrm{Bw} 400$ were taken as better parents in cross 1 and cross 2, respectively. Parents of both crosses were found to be significantly different for leaf length. Means of $\mathrm{F}_{1}(42.31 \pm 7.05)$ and $\mathrm{P}_{1}(41.36 \pm 1.66)$ were not significantly different and hence heterosis was not found in cross 1 for leaf length. The leaf width of $F_{1}$ plants in both crosses was significantly higher than that of the better parent, $\mathrm{Bg}$ 379-2 showing heterosis. Significant positive heterosis was found only in cross 2 for taller culms, though the parents in both cross showed significant differences for culm length.

Days to $50 \%$ flowering between parents in cross 1 (76.25 and 95.75) showed significant difference, while that of the parents in cross 2 (95.5 and 95.75) was not significantly different. When comparing means of $\mathrm{F}_{1}$ with its $\mathrm{P}_{1}$ and $\mathrm{P}_{2}$, the cross 1 did not show heterosis, while in cross 2, negative heterosis was observed for days to $50 \%$ flowering. In both crosses, no heterosis was observed for mean tiller number.

$\mathrm{F}_{1}$ plants had longer panicles than both parents and thus panicle length showed significant positive heterosis in cross 1. However, in cross 2, mean panicle length of $F_{1}$ (28.26) was not higher than the mean panicle length of $P_{1}$ (29.35) and thus no heterosis was observed. Positive and significant heterosis was observed for plant height in both crosses. Alam et al., (2004) and Nuruzzaman et al., (2002) reported negative heterosis for rice plant height in several crosses.

Heterosis was absent in both crosses for the panicle number per plant. Although higher panicle weight in $F_{1}$ than the better parent was expected, $F_{1}$ plants of both crosses did not show positive heterosis, but a negative heterosis was observed in cross 2 . To increase grain yield in rice, varieties with higher grain weight and more panicles per plant could be selected. A high percentage of heterosis for grain yield and its related traits were reported by Zhang et al., (1994), Li et al., (2002) and Alam et al., (2004).

Characters such as culm length (-0.03), panicles per plant (-0.02) and panicle weight $(-0.08)$ showed negative heterobeltiosis and relatively higher heterobeltiosis was found in leaf width $(0.2)$, panicle length $(0.16)$ and seedling vigor (0.15) in Cross 1. Positive heterobeltiosis values were obtained for seedling vigor (0.03), leaf width (0.45), culm length (0.11), and plant height (0.07) and the other characters showed negative heterobeltiosis in Cross 2.

\section{The components of means}

Parents $\left(\mathrm{P}_{1} \& \mathrm{P}_{2}\right)$ and their $\mathrm{F}_{1} \mathrm{~s}$ in both crosses were analyzed to determine the genetic components of means by assuming that there is no non allelic interaction for the characteristics that were scored in the study. The measure of the effect of the genes which the parents have in common (m), additive genetic component ([d]) and dominance genetic component ([h]) of each character were tabulated separately for both crosses in Table 03. Numerical value of [h] was greater than [d] for seedling vigor, leaf length, leaf width, culm length, and plant height in both the crosses indicating that the genes for those characters were dispersed between parents. The same was observed for panicle length in cross 1 and related traits of number of tillers and number of panicles per plant in cross 2 . Negative [h] values for seedling vigor and panicle weight in cross 2 indicated the Cross 1 to be more potential to extract new segregates that are superior for higher seedling vigour with heavy panicles. Similarly negative [h] for days to $50 \%$ flowering will provide an opportunity to extract short age lines from cross 1 . The cross 1 also shows potential to have shorter culms with longer panicles than cross 2 as indicated by respective [d] and [h] values in Table 03 . 
Table 03: Genetic effects of yield related agronomic characteristics of rice estimated using the cross between Bg 379-2 and Mu 8-7 and the cross between Bg 379-2 and Bw 400

\begin{tabular}{|c|c|c|c|c|c|c|c|c|c|c|}
\hline \multirow{2}{*}{$\begin{array}{l}\text { Cross/ } \\
\text { Genetic effect }\end{array}$} & \multicolumn{10}{|c|}{ Characteristics } \\
\hline & $\mathrm{SH}$ & $\mathrm{DF}$ & $\mathrm{LL}$ & LW & $\mathrm{CL}$ & PL & $\mathrm{PH}$ & $\mathrm{TP}$ & PP & PW \\
\hline \multicolumn{11}{|l|}{$\begin{array}{l}\text { Cross 1: Bg } \\
\text { 379-2 x Mu8-7 }\end{array}$} \\
\hline $\mathrm{m}$ & 18.1 & 85.9 & 39.5 & 1.3 & 70.3 & 27.7 & 97.1 & 11.6 & 9.9 & 41.3 \\
\hline [d] & 0.45 & 9.75 & 1.95 & 0.1 & 2.45 & 0.45 & 2.0 & 0.15 & 0.15 & 9.5 \\
\hline$[\mathrm{h}]$ & 6.85 & 8.9 & 2.8 & 0.4 & 0.6 & 3.3 & 4.9 & 0.2 & -0.1 & -4.2 \\
\hline \multicolumn{11}{|l|}{$\begin{array}{l}\text { Cross 2: Bg } \\
379-2 \text { x Bw } 400\end{array}$} \\
\hline $\mathrm{m}$ & 18.9 & 95.6 & 49.8 & 1.4 & 77.5 & 26.5 & 105.6 & 11.5 & 9.8 & 45.7 \\
\hline [d] & 1.3 & 0.1 & 8.4 & 0.0 & 9.1 & 0.15 & 10.5 & 0.25 & 0.0 & 5.2 \\
\hline$[\mathrm{h}]$ & 5.3 & -7.1 & 3.4 & 0.7 & 18.6 & 1.8 & 18.7 & -0.3 & -0.5 & -19.9 \\
\hline
\end{tabular}

$\mathrm{SH}=$ Seedling height, $\mathrm{DF}=$ Days to $50 \%$ flowering, $\mathrm{LL}=$ Leaf length, $\mathrm{LW}=$ Leaf width, $\mathrm{CL}=\mathrm{Culm}$ length, $\mathrm{PL}=\mathrm{Panicle}$ length, $\mathrm{PH}=\mathrm{Plant}$ height, $\mathrm{TP}=$ Number of tillers per plant, $\mathrm{PP}=$ Number of panicles per plant, $\mathrm{PW}=\mathrm{Panicle}$ weight

$\mathrm{m}=$ Mid parent value

[d] = Additive genetic effect

$[\mathrm{h}]=$ Dominance effect

Ten characteristics of the two crosses were investigated along with their parents and the genetical architecture of those characters was found based on the means of each character. The parents significantly differ for most of the characters but not for SH, PL, TP and PP in Cross 1 or for days to $50 \%$ flowering, $\mathrm{LW}$, TP and PP In cross 2 (Table 01 and 02). Cross 1 showed significant $F_{1}$ heterosis for $L W, P L$ and $\mathrm{PH}$ and cross 2 showed for LW, CL and $\mathrm{PH}$. The genetical architecture of the crosses was assumed as simple type, in that the genes controlling these characters displayed additive and dominance effects only. Since $[\mathrm{h}]>[\mathrm{d}]$ for SV, LL, LW, CL, PL, and PH in Cross 1, and for seven characters in cross 2 (Table 03), the genes determining these characters appear to be dispersed between parents. This suggests that the recombinant inbred lines extracted from these crosses should show transgressive variation for these characters.

\section{CONCLUSION}

The Cross, Bg379-2 X Mu 8-7 can be considered as a more potential cross especially to extract short age and high yielding or comparable breeding lines which identified for further advancement to develop pure lines with the greater vigour.

\section{REFERENCES}

Abeysiriwardena, D.S. de Z. (2003). Rice varietal improvement for future challenges. In Rice congress. Department of Agriculture, Sri Lanka.

Alam, M. F., M. M. R. Khan, M. Nuruzzaman, S. Parvez, A. M. Swaraz, I. Alam, and N. Ashan. (2004). Genetic basis of heterosis and inbreeding depression in rice (Oryza sativa L.). Journal of Zhejiang University (Science). pp.406- 411. 
Birchler, J. A., L. A. Donald and N. Riddle. (2003). In search of molecular basis of heterosis. Plant Cell. 15, pp. 2236-2239.

Gupta, S. K. (2000). Plant Breeding: Theory and Techniques. Published by Updesh Purohit for Agrobios, India.

Jones, J. W. (1926). Hybrid vigor in rice. Journal of the American Society of Agronomy. 18, pp. 423428 .

Kim, C. H. (1985). Studies on heterosis in F1 using cytoplasmic genetic male sterile lines of rice (Oryza sativa L.) (in Korean, English summary). Research Report RDA (Crops).

Li, W., J. Z. Zhang, G. Q. Zhang and Q. F. Zuo. (2002). Analysis of Heterosis of Main Agronomic Traits in Indica-Japonica Lines of Rice. Journal of Southwest Agricultural University. 24(4), pp. 317-320.

Nuruzzaman, M., M. F. Alam, M. G. Ahmed, A. M. Shohael, M. K. Biswas, M. R. Amin, and M. M. Hossain. (2002). Studies on Parental Variability and Heterosis in Rice. Pakistan Journal of Biological Science. 5(10), pp. 1006-1009.

Parvez, S. (2006). Recent advances in understanding genetic basis of heterosis in rice (Oryza sativa L.). Revista UDO Agricola. 6(1), pp. 1-10.

Yuan, L. P., Z. Y. Yang and J. B. Yang (1994). Hybrid rice in China. In: Hybrid rice technology: New development and future prospects (SS Virmani, ed.). IRRI, Philippines, pp.143-147.

Zeigler, R. S. and A. Barclay. (2008). The relevance of rice. Rice. Springer LA 1, pp. 3-10.

Zhang, Q., Y. J. Gao, S. H. Yang, R. A. Ragab, M. A. S. Maroof and Z. B. Li. (1994). A Diallel Analysis of Heterosis in Elite Hybrid Rice based on RFLPs and Microsatellites. The Applied Genetics. 89, pp. 185-192. 